\title{
NORMATIVIDADE AMBIENTAL E OCUPAÇÃO IRREGULAR EM MANANCIAIS DE MUNICÍPIOS PEQUENOS
}

\author{
ENVIRONMENTAL REGULATIONS AND IRREGULAR \\ OCCUPATION IN SPRINGS OF SMALL CITIES
}

Ilton Garcia da Costal

Carolina Harumi Assahara ${ }^{2}$

\begin{abstract}
RESUMO
O presente estudo visa analisar a invasão de áreas de preservação permanente, principalmente próximas a mananciais na zona urbana, em municípios de pequeno porte localizados na Região Metropolitana de Londrina (PR). Busca-se explanar a importância do meio ambiente e da moradia para a possibilidade de vida digna, além das implicações decorrentes do exercício dos mesmos, bem como as consequências resultantes da omissão do Poder Público frente as referidas prerrogativas, tencionando salientar o conflito entre as normas de Direitos fundamentais explícitas na Carta Política, no Plano Diretor e demais regulamentos sobre o solo urbano, que se direcionam contra essas perspectivas, por meio de estudos de normas e instrumentos governamentais, os quais objetivam o desenvolvimento social conjuntamente com a concretização de um ambiente ecologicamente sustentável. Utilizou-se o método dedutivo com base em pesquisas bibliográficas em doutrinas e revistas científicas, tal como dados quantitativos de órgãos governamentais pertinentes ao tema. Visa-se a exploração de possíveis medidas a serem realizadas pelos órgãos competentes para a garantia do bem comum da comunidade, observando os princípios presentes no ordenamento jurídico vigente.
\end{abstract}

\section{PALAVRAS-CHAVE:}

Áreas de Preservação Permanente; meio ambiente; Plano Diretor; moradia; solo urbano; ponderação de princípios.

\footnotetext{
ABSTRACT

The present study aims to analyze the invasion of areas of permanent preservation, mainly near to springs in the urbane zone, in municipal districts of small load located in the Metropolitan

${ }^{1}$ Doutor e Mestre em Direito - PUC -SP, Professor do Doutorado, Mestrado e Graduação em Direito da UENP Universidade Estadual do Norte do Paraná, Líder do Grupo de Pesquisa em Constituição, Educação, Relações de Trabalho e Organizações Sociais - GPCERTOS, Mestre em Administração, Ex Presidente de Comissão de Estágio, ex vice-presidente da Com Ensino Jurídico OAB SP, ex Membro do Comitê de Área da Fundação Araucária de Pesquisa do Paraná. Matemático e Advogado. e-mail iltongcosta@gmail.com

${ }^{2}$ Membro do Grupo de Pesquisa em Constituição, Educação, Relações de Trabalho e Organizações Sociais GPCERTOS. (registrado no CNPq) UENP Universidade Estadual do Norte do Paraná E-mail: caro1060592@gmail.com
} 
Region of Londrina (PR). It is looked for to explain the importance of the environment and of the dwelling for the possibility of worthy life, besides the current implications of the exercise of the same ones, as well as the resulting consequences of the omission of the Public Power front referred them prerogatives, intending to point out the conflict among the explicit norms of fundamental rights in the Political Letter and legislative actions that they are addressed against those perspectives, through studies of norms and government instruments, which aim the social development jointly with the materialization of an atmosphere ecologically maintainable. The present work used the deductive method based on literature searches in scientific journals and doctrines, such as quantitative data relevant government agencies to the subject. Besides, the exploration of possible measures is aimed to be carried out by the competent organs for the guarantee of the well-being of the community, observing the beginnings attested in the effective juridical planning.

\section{KEYWORDS:}

Permanent Preservation Areas, environment, Key Plan, dwelling, urban ground, weighting of principles

\section{INTRODUÇÃO}

A qualidade de vida é um dos objetivos que o Poder Público procura alcançar através da construção de uma sociedade justa, livre e solidária. A sua relação com o meio ambiente ecologicamente sadio e sustentável se correlaciona ao direito à vida, resultando em um direito fundamental.

Situações pertinentes a desastres ambientais ocorridos na zona urbana e invasões de áreas de preservação para construção de moradias destinadas a população de baixa renda são comuns na contemporaneidade. Contudo, a dimensão do transtorno tende a ser maior em municípios pequenos.

Devido ao processo de evolução social, com o advento da globalização e o crescimento da economia, provocou-se a expansão desigual da malha urbana, onde determinado grupo de indivíduos se veem sujeitos a formas de sobrevivência irregulares. A falta de informações relacionadas ao tema somados a ausência de fiscalização, omissão legislativa municipal e políticas públicas direcionadas a programas habitacionais e o planejamento e oferta do solo urbano fomentam a prática desordenada de ocupações próximas a mananciais, ocasionando 
posteriormente, demais problemas socioambientais. Esses assentamentos, além de não atenderem à função social da cidade, como se apresenta no art. 182 da Constituição Federal, infringem o direito ao meio ambiente ecologicamente equilibrado, previsto no art. 225 da aludida Carta Política.

A problemática envolve questões administrativas, sociais e ambientais, nas quais, o critério de sustentabilidade somente alcançará seu equilíbrio ao equiparar o crescimento econômico, desenvolvimento humano e a preservação ambiental. A sobreposição de um fator sobre o outro provoca a instabilidade de todo sistema, reafirmando o conflito entre princípios fundamentais de direito humano: o direito à moradia e o direito ao meio ambiente ecologicamente sadio.

Pelo método dedutivo, com embasamento legal, doutrinário e quantitativo, objetiva-se estabelecer a compreensão de questões relacionadas à proteção jurídica do meio ambiente como um todo, as áreas de preservação permanente e a exploração de medidas aplicadas pelos órgãos do executivo de cidades pequenas que compõem a Região Metropolitana de Londrina, no Paraná, em consonância com a legislação ambiental e a Constituição Federal, seus impactos e divergências legais, juntamente com a problemática social do direito à moradia, ponderando-se os direitos fundamentais abordados, de modo a analisar medidas viáveis para conter a propagação do problema.

\section{O DIREITO AMBIENTAL COMO UM DIREITO FUNDAMENTAL}

À proteção jurídica do meio ambiente é uma realidade relativamente recente nos panoramas constitucionais nacional e internacional, iniciada pós Segunda Guerra, pela junção de diversos fatores e elementos históricos, sociais, políticos, econômicos e científicos, não havendo um consenso exato na doutrina brasileira ou mundial sobre seu referido conceito.

No entanto, é possível observar uma certa preocupação com os recursos naturais desde o direito romano, em especial, quanto à limpeza das águas, à fumaça e à preservação de áreas 
plantadas. Porém, esta atenção era restrita a questões de imóveis ou propriedade privada, atrelada apenas a perspectiva econômica.

Entende-se por Meio Ambiente o conjunto de fatores bióticos e abióticos capazes de provocar efeitos de modo direto ou indireto, em prazo indeterminado sobre os seres vivos. A Lei 6.938/1981, que estabelece a Política Nacional do Meio Ambiente (PNMA), em seu art. $3^{\circ}$, I, define

I - meio ambiente, o conjunto de condições, leis, influências e interações de ordem física, química e biológica, que permite, abriga e rege a vida em todas as suas formas;

Segundo o Conselho Nacional do Meio Ambiente (CONAMA), órgão consultivo e deliberativo do Sistema Nacional do Meio Ambiente - SISNAMA, compreende-se meio ambiente como o conjunto de condições, leis, influências e interações de ordem física, química, biológica, social, cultural e urbanística, que permite, abriga e rege a vida em todas as suas formas

\begin{abstract}
A expressão meio ambiente se manifesta mais rica de sentido (como conexão de valores) do que a simples palavra ambiente. Esta exprime o conjunto de elementos; aquela expressa o resultado da interação desses elementos. $\mathrm{O}$ conceito de meio ambiente há de ser, pois, globalizante, abrangente de toda a natureza original e artificial, bem como os bens culturais correlatos, compreendendo, portanto, o solo, a água, o ar, a flora, as belezas naturais, o patrimônio histórico, artístico, turístico, paisagístico e arqueológico.
\end{abstract}

O meio ambiente é, portanto, um conceito extremamente amplo, que não comporta uma simples análise restrita, "dada sua característica de transversalidade e multidisciplinaridade, que o identifica com uma diversidade de significados”. (PADILHA, 2010, p. 195).

De suma importância, denota-se que, com o desenvolvimento do mercado globalizado, ocasionou-se a degradação da qualidade de vida e da saúde da população, cumulando-se com a devastação dos recursos naturais. A crescente evolução tecnológica incrementou um período de "rápido descarte”, baseado na concorrência empresarial, aceleração da urbanização e aumento do mercado consumidor, bem como a expansão de multinacionais, fomentando transformações que impõem uma nova ordem social, englobando aspectos que se estendem desde o contexto político ao legal.

Historicamente, o bem ambiental, enquanto objeto suscetível de apropriação, "era considerado pelo Direito Clássico como res nullius, ou coisa de ninguém, entretanto suscetível 
de uso para todos, pois acreditava-se que o meio ambiente era infinito e inesgotável". (PADILHA, 2010, p. 195). Destarte, reconhecia-se o meio ambiente como um patrimônio público, de uso coletivo e passível de apropriação.

A questão que se busca levantar persiste no fato de o bem ambiental ser caracterizado como autônomo, imaterial e generalizado, superior a qualquer classificação de bem público ou privado, ou seja, "trata-se de um direito metaindividual, de alta complexidade na sua identificação, não possuindo um titular certo nem objeto divisível" (PADILHA, 2010, p.43), pois todos os indivíduos são considerados detentores deste direito, sendo formalmente e materialmente fundamental, pois encontra-se positivado na Lei Maior, que em ser art. 225 afirma que todos os sujeitos possuem direito ao meio ambiente ecologicamente equilibrado, sendo este essencial para a sadia qualidade de vida, atribuindo ao poder público concomitantemente a coletividade o papel de defesa e preservação com vistas na presente e para as gerações futuras, tratando-se de condição indispensável para a realização da dignidade da pessoa humana, princípio de todos os direitos fundamentais. Neste prisma, afirma Costa e Giacóia (2015, p.192)

O artigo 225, caput da Constituição Federal eleva o Direito Ambiental ao patamar dos direitos humanos fundamentais. Ele reafirma que o meio ambiente é um bem de uso comum do povo e essencial a sadia qualidade de vida, fazendo com que estes bens ambientais sejam integrados na categoria jurídica de coisa comum a todos (rescomune ominium).

O Direito ao meio ambiente é visto como algo que está situado acima das divisões entre classes sociais, gêneros, etnias, pois é uma prerrogativa que se expande para direitos de natureza social. Em termos valorativos, pode-se afirmar que a obtenção de um ambiente saudável precede a existência da própria vida, uma vez que esta, sem qualidade, não passa de um simples estado inconsciente, sob o ponto de vista racional. Para Lopes e Zerbini (2016, p.56)

O reconhecimento do direito a um meio ambiente sadio configura-se, na verdade, como extensão do Direito à vida, quer sobre o enfoque da própria existência física e saúde dos seres humanos, quer quanto ao aspecto da dignidade desta existência.

Desta forma, o meio ambiente inserido na zona urbana é a ligação do conjunto de elementos naturais, artificiais e culturais que proporcionam o desenvolvimento de maneira equilibrada da vida em todas as suas formas, sendo denominado como meio ambiente artificial. 
Para tal, não se pode falar em supervivência humana digna ou em meio adequados sem levar em conta um meio ambiente balanceado e oportuno de modo a conceder o bem-estar da qualidade de vida que todos tencionam, pois, a proteção ambiental encontra-se indissociavelmente interligada aos direitos humanos, visto que as adversidades ambientais são multidimensionais, compondo-se de aspectos humanos, que são diretas ou indiretamente afetados pelos danos ambientais.

Assim, compete a todas as entidades políticas a proteção do meio natural, sendo atribuição administrativa comum, pois concerne-se de uma prerrogativa abrangente atrelado ao direito à vida e a integridade pessoal. Logo, se estabelece um novo paradigma de Estado socioambiental de direito, onde preserva-se as características qualitativas do ambiente, em uma dimensão natural e artificial para as próximas gerações. Contudo, o Direito ambiental acaba sendo sobreposto em relação a omissão governamental, que busca sanar determinados problemas em detrimento de outros.

\section{1 Áreas de Preservação Permanente}

Áreas de Preservação Permanente se destinam a proteção dos solos, recursos hídricos e vegetação primitiva, exercendo papel ecológico de preservação da fauna e flora, controlando possíveis desastres ambientais (erosão, assoreamentos, poluição, etc.). Em suma, possuem as funções hidrogeológica e antierosiva de vegetação, conforme previsto na Lei n $12.651 / 2012$ em seu Art. $3^{\circ}$, II

II - Área de Preservação Permanente - APP: área protegida, coberta ou não por vegetação nativa, com a função ambiental de preservar os recursos hídricos, a paisagem, a estabilidade geológica e a biodiversidade, facilitar o fluxo gênico de fauna e flora, proteger o solo e assegurar o bem-estar das populações humanas;

As Áreas de Preservação Permanente se apresentam como demarcações ao direito de propriedade e de utilidade socioambiental, não se restringindo apenas a imposição de um simples Poder Público. Sua localização no meio urbano tem por fundamento a defesa da biodiversidade, concomitantemente a segurança social, à medida que favorece a afirmação da dignidade da pessoa humana, ressaltando seus direitos a um meio ambiente sadio e equilibrado. 
O desmatamento destes locais, tanto de modo parcial quando total, tem ocorrido independe da execução de atividades relacionadas ao setor público ou ao interesse social. Ademais, devem seguir o Plano Diretor e as leis de uso e ocupação do solo do respectivo município, observando as restrições impostas pelas leis ambientais vigente, ou seja, não se torna possível a supressão da cobertura vegetal em áreas de preservação permanente justamente devido as suas importantes funções ecológicas. As retiradas das áreas verdes nativas apenas ocorrerão em casos de utilidade pública, isto é, de relevante interesse social, segundo o art. $3^{\circ}$, IX, "d" no Novo Código Florestal

\footnotetext{
Art. $3^{\circ}$ Para os efeitos desta Lei, entende-se por:

IX - Interesse social:

d) a regularização fundiária de assentamentos humanos ocupados predominantemente por população de baixa renda em áreas urbanas consolidadas, observadas as condições estabelecidas na Lei $\mathrm{n}^{\circ} 11.977$, de 7 de julho de 2009;
}

Portanto, compete apenas a organizações federais e estaduais, unidos e de modo comprovado a utilidade pública ou extremo interesse social coletivo do empreendimento e a inexistência de qualquer outra alternativa técnica de outro local para executar determinada função, para que se possa abrir exceção e autorizar o uso e até mesmo o desmatamento de APPs.

\subsection{Os Mananciais}

Não é possível afirmar a existência de um desenvolvimento harmônico sem a recuperação e conservação da qualidade da água do abastecimento público, ao passo que a disponibilidade do recurso hídrico é considerada um dos fatores limitativos do desenvolvimento. Logo, tem-se os mananciais que correspondem a fontes de água doce superficiais ou subterrâneas, utilizadas para o consumo humano ou para desenvolvimento de funções econômicas, fundamentando sua importância ao fato de servirem como fontes de abastecimento de águas, e, sua manutenção em qualidade e quantidade são essenciais à saúde e ao bem-estar social. Assim, suas áreas carecem de atenção específica, contemplando aspectos legais e gerenciais.

Nas últimas décadas, a atividade antrópica tem contribuído para o seu desgaste cada vez mais acentuado na zona urbana, ocasionado pelo apoderamento do solo e práticas inadequadas no mesmo; mal-uso de recursos hídricos; omissão de infraestrutura de saneamento 
(instabilidade dos sistemas de esgoto sanitário, manuseio de águas pluviais e resíduos sólidos); retirada da cobertura vegetal; erosão e assoreamento de rios e córregos; e atividades industriais que se desenvolvem de maneira ilegal em relação à legislação ambiental.

A Lei 6.766/79, que dispõe sobre o parcelamento do solo urbano, prevê em seu art.13 a proteção dos mananciais, ao discipliná-lo como responsabilização por parte do Estado

Art. 13. Aos Estados caberá disciplinar a aprovação pelos Municípios de loteamentos e desmembramentos nas seguintes condições

I - quando localizados em áreas de interesse especial, tais como as de proteção aos mananciais ou ao patrimônio cultural, histórico, paisagístico e arqueológico, assim definidas por legislação estadual ou federal;

Tais locais, ainda que respaldado pela legislação constitucional e infraconstitucional, são ocupadas em sua maioria, considerando a facilidade do acesso aos recursos hídricos. A manutenção deste quadro interfere na baixa qualidade de água distribuída, expondo uma parcela significativa da população a doenças, devido a omissão fiscal e falta de planejamento e condições necessárias, ambos previstos no Estatuto da Cidade, isto é, ocorre em decorrência da inexistência ou aperfeiçoamento de um Plano Diretor que controle as ações em território municipal. A amenização destes problemas tem como base, a aplicação de recursos de tratamento de água, ou sistemas mais complexos de adução, os quais demandam um grande investimento, muitas vezes inacessíveis a pequenos municípios.

\section{INVASÃO DE ÁREAS DE PRESERVAÇÃO PERMANENTE NA ZONA URBANA}

Como se verifica, o município não pode ser entendido como um território isolado, uma vez que advém de consequências advindas da globalização. Tal fenômeno é resultado direto do desenvolvimento científico e tecnológico, o que acarreta também, a fragmentação nas formações territoriais, sociais e políticas. Conforme Fiorillo (2013, p. 589), a cidade apenas cumpre sua função social ao conceder aos seus habitantes os direitos fundamentais e sociais à qualidade de vida digna.

A propriedade urbana assume característica de função ambiental ao desconsiderar a ideia de simples imóvel localizado nos limites estipulados pelo legislador infraconstitucional, 
passando a contemplar os valores que fomentam a dignidade da pessoa humana na esfera jurídica. As questões ambientais urbanas refletem problemas sociais que se vislumbram com muito mais intensidade do que em outros meios.

A característica afastada das Áreas de Preservação Permanente (APP), juntamente com sua "intocabilidade", ocasiona sua auto degradação, realizada por próprios membros da comunidade, os quais foram "esquecidos" no planejamento urbano e social local, que ao tomarem conhecimento do "isolamento", oriundo da ausência de policiamento do poder público e de outros órgãos responsáveis por sua proteção, permite-se que proceda os usos nocivos naquele espaço, dos quais se destaca a ocupação humana para fins habitacionais. Como consequência, é possível destacar a transformação destes locais e em seu entorno, em espaços marcados pela insuficiência de políticas públicas para garantia de condições dignas mínimas a sobrevivência do ser humano.

Salienta Granziera (2014, p. 642) que "se a lista relativa às diretrizes a serem observadas na busca da cidade sustentável envolve questões que extrapolam o tema ambiental, o meio ambiente é um fator transversal da melhoria ou da queda da qualidade de vida nas cidades".

\subsection{Ocupação em áreas de mananciais em pequenos municípios}

A invasão humana em locais de mananciais para implantação de domicílios é comumente conhecida por ocupações informais. Conforme dados do Instituto Brasileiro de Geografia e Estatística (IBGE, 2017), a proporção de municípios com ocorrência de situações relacionadas à precariedade nas condições de moradia provenientes de loteamentos irregulares e/ou clandestinos era de 71,9, em cidades com população até 50.000 habitantes. No Paraná, segundo pesquisa de 2019 da Companhia de Habitação do Paraná (COHAPAR), há registro de 260 loteamentos e 21.737 domicílios sobre áreas de preservação ambiental e, 297 loteamentos e 27.055 domicílios sobre ou margeando leito de curso de água. Na mesma pesquisa, em relação aos 25 municípios que compõem a Região Metropolitana de Londrina, foram identificados um total de 4 loteamentos e 511 domicílios, localizados em três cidades, duas delas com população inferior a 20.000 habitantes. 
No município de Centenário do Sul, foi registrado o loteamento “Área de Preservação Permanente" com um total de 100 domicílios sem rede de esgoto e evidente possibilidade de contaminação das águas. Já no município de Assaí, que possui o córrego da Sede e córrego Passo Fundo, afluentes do rio Tibagi, responsável pelo abastecimento hídrico da cidade, foram catalogados 2 loteamentos, totalizando 81 domicílios, localizados "Chácara Duarte”, que conta com 44 edificações, das quais 6 necessitam de realocação; e outro na "Vila Minami", com 37 moradias, sendo necessário a apuração da quantidade de edificações para o reassentamento parcial.

Tais apropriações possuem diversas origens, das quais se pode citar o excesso ou imprecisões nas regulamentações e ações estatais, o que implicam no impedimento de moradias em locais regulares por motivos burocráticos e excessivo custo das terras, simultaneamente a negligência acerca da perpetuação dos mesmos. Outro problema se dá devido ao prolongamento da ausência de incentivo e investimentos no mercado imobiliário regular de modo a abrigar a população de baixa renda, o que reflete o aparecimento de negócios paralelos e prejudiciais às leis, ao planejamento urbano e principalmente, ao meio ambiente. Destaca-se que "o crescimento acelerado da população mundial e sua migração em massa das zonas rurais para as urbanas, com o consequente aumento da poluição urbana, gerou a preocupação com o planejamento populacional, como forma de proteção ao meio ambiente" (FREITAS, 2000, p. 114). Outrossim, pontua-se a facilidade de acesso a recursos hídricos nestes espaços, que, contudo, possui duas vertentes: uma favorável, a qual se dá devido ao acesso irrestrito da água; e uma desfavorável, pertinente a ocupação nestes locais, que podem ocasionar problemas, tal como poluição, devido a contaminação pelo esgoto doméstico e a redução da capacidade de reposição hídrica para os reservatórios.

Os recursos hídricos são encarados como bens de domínio público, difuso e de uso comum à sociedade, dado como recurso natural limitado de valor econômico, carecendo-se de ser decentralizada e equilibrada entre detentores do poder e consumidores.

Consoante análise elaborado pela Agência Nacional de Águas (ANA, 2015), em municípios com população inferior a 50.000 habitantes no estado do Paraná, verificou-se a presença de 129 mananciais superficiais/mistos e 213 mananciais subterrâneos destinados a abastecimento público. De acordo com o Plano Nacional de Recursos Hídricos (PNRH), estabelecido pela Lei $n^{\circ}$ 9.433/97, a utilização da água deve estar sempre vinculada de modo a 
atender os interesses coletivos, buscando assegurar a atual e futuras gerações a disponibilidade do recurso de modo qualitativo e quantitativo, junto a sua utilização racional, com vistas ao desenvolvimento sustentável.

Porém, a insuficiência das políticas públicas ambientais prejudica a particularidade das águas, impossibilitando seu uso. Para a manutenção sustentável, é preciso o desenvolvimento de instrumentos gerenciais de proteção, planejamento e utilização, adequando o planejamento urbano à vocação natural do sistema hídrico, alcançado através de medidas asseguradas pela gestão municipal, noutros termos, para que isso seja possível, há a necessidade de uma política de habitação adequada, saneamento básico amplo, distribuição de água para todos os habitantes, trabalho e salário digno a todos. Para uma condição íntegra de vida, o Poder Público deve colocar à sua disposição os direitos sociais previstos no art. $6^{\circ}$ da Constituição Federal.

\subsection{O direito à moradia como um direito fundamental}

A busca por moradia permeia a sociedade deste a sedentarização do ser humano que, através dos tempos passou a ser mais que um simples abrigo, tornando-se algo indispensável, um benefício no qual se consubstancia materialmente em um bem imóvel, ao passo que como atributo concreto só poderá ser concebido no direito à propriedade. Demonstra Barcellos e Barroso (2003, p. 171) que para se estabelecer o direito a dignidade humana, deve-se sempre considerar que o homem depende das condições materias de subsistência.

O Direito a moradia concilia-se com o chamado "direito à cidade", ou seja, a prerrogativa de acesso ao saneamento básico, a educação, à saúde, à cultura, ao lazer, ao trabalho, etc., os quais, quando de fato são assegurados, velem-se de importante agente de inclusão social, estabelecido como direito social fundamental pela Constituição, em seu art. $6^{\circ}$, dado que partindo da ideia de dignidade da pessoa humana ( $\left.\operatorname{art} .1^{\circ}, \mathrm{III}\right)$, direito à intimidade e à privacidade $\left(\operatorname{art} .5^{\circ}, \mathrm{X}\right)$ e de ser a casa asilo inviolável (art. $\left.5^{\circ}, \mathrm{XI}\right)$, não existe dúvidas de que o direito à moradia busca consagrar o direito à habitação digna e adequada.

Não obstante, o Brasil ainda possui déficit habitacional em muitos locais, devido as diferenças sociais, onde a classe desfavorecida e destituída economicamente, socialmente e politicamente, não possui uma moradia adequada em decorrência do processo de estruturação 
social enraizado, que beneficiou o controle da propriedade àqueles detentores do poder de compra, fazendo com que estes cidadãos "desabrigados" desloquem-se para áreas protegidas ambientalmente, as quais em geral são mais afastadas do centro, a fim de edificar moradias, ainda que em situações de ilegalidade e desprovida de segurança, facilitada pela omissão do poder público em relação a implementação de novas políticas de habitação, o que gera a aquisição da terra sem título de compra ou posse. A ocupação ilegal pauta-se no direito à propriedade, assegurado pela Carta Magna, no caput do art. $5^{\circ}$ e reafirmado em seu inciso XXII.

A alegação do direito à propriedade é interpretada conjuntamente com a questão do cumprimento da função social, caracterizado como centro da atividade do domínio urbano, isto é, converte-se como principal função da propriedade citadina cumprir seus deveres, sendo estes o favorecimento da comunidade na qual ela se insere, devendo ser exercido de forma consciente, progredindo a realização do ser humano, e da vida social digna. De acordo com Vanin (2015, p. 44-45), um dos problemas remete-se a difícil regulação do mercado imobiliário, em função de a propriedade privada ser considerada como um direito absoluto, de difícil limitação ou conformação com os interesses socioambientais.

Entretanto, essa prerrogativa é visualizada de modo diferente em relação a problemática em questão, na qual envolve discussões ambientais e sociais, sendo entendido como bem de uso limitado, com objetivo de garantir a sua utilização racional, equiparando as necessidades sociais e as obrigações de uso sustentável a luz do Novo Código Ambiental. A função social da propriedade, deste modo, é atingida quando atende às exigências dispostas no Plano Diretor, regulada pela Lei ${ }^{\circ} 10.257 / 01$, em seu art. 39 em consonância com o art. $2^{\circ}$, não podendo ser interpretada de modo literal e isolado.

Em contrapartida, deve-se compreender que o direito à moradia é uma norma de eficácia imediata, e consequentemente, autoaplicável, a qual deriva-se da necessidade de segurança dos indivíduos, que não se confina a apenas a existência de um lugar simples para morar, mas sim de uma habitação que possua condições básicas, concedendo o pleno exercício de suas potencialidades e seus direitos, ou seja, sem ela não há garantias para a efetivação de outros direitos inerentes ao homem.

Para tanto, é necessária a fixação de diretrizes nacionais de saneamento básico, tais como a universalização de acesso; integralidade; abastecimento de água, esgotamento sanitário, 
limpeza urbana e manejo de recursos sólidos; e principalmente, a articulação entre as políticas de desenvolvimento urbano e regional, de habitação, de combate à pobreza e de sua erradicação, bem como a proteção ambiental.

Para que haja sua concretização é necessário a atuação positiva do Estado, por meio de políticas públicas, onde deverão ser adotados programas eficientes e mobilizações políticas que busquem seu cumprimento, simultaneamente com os assuntos relacionados ao meio ambiente sustentável, de modo a igualar ambos, não havendo sobreposição ou conflito entre eles, paralelamente com o estímulo a implantação de infraestruturas e serviços comuns aos municípios mediante a mecanismos de cooperação entre os entes federados.

\section{CONFLITO ENTRE PRINCÍPIOS: O DIREITO AO MEIO AMBIENTE E O DIREITO A MORADIA}

Como mencionado, a invasão em áreas de mananciais em pequenos municípios evidencia problemas ao meio natural e também, no que diz respeito à moradia adequada, sendo os dois, direitos fundamentais para que haja condições dignas mínimas de sobrevivência humana.

O debate se dá ao questionamento de como oferecer meios habitacionais adequados sem que ocorra a degradação ambiental, isto é, como impedir que os cidadãos de baixa renda ocupem áreas de preservação permanente dando-lhes uma moradia adequada em locais propícios para tal, conforme os ditames da administração pública.

As consequências oriundas dessas ocupações irregulares manifestam-se por meio da poluição dos recursos hídricos e dos mananciais, banalização de mortes por contaminação e, consequentemente, difusão de epidemias e demais riscos decorrentes de prováveis ocorrências de catástrofes naturais. Consoante Granziera (2014,p. 630) “esse cenário e os seus rebatimentos na saúde das pessoas, no sossego público e, de uma forma geral, na qualidade de vida revela a importância de buscar alternativas realistas para tornar mais equilibrado e menos caótico o espaço urbano". 


\subsection{Normatividade Ambiental}

A Conferência de Estocolmo, realizada em 1972, teve importante influência na transformação da legislação ambiental interna dos países participantes nos anos subsequentes, contribuindo para uma visão mais holística do meio ambiente.

A divisão de competências constitucionais adotadas no país aplica a descentralização ambiental de acordo com o ente político (União, Estado e Município), o que torna a questão de aplicação e implementação de políticas públicas voltadas ao tema extremamente complexa, o qual envolve órgãos de Administração direta e indireta nos diversos níveis da Federação, exigindo processos de reconhecimento, planejamento, levantamento de informações e, de estudos científicos extremamente abrangentes, que impõem a participação de profissionais de diversas áreas, implicando em um processo de atuação de índole multidisciplinar. Trata-se da denominada competência material ou administrativa comum, previstas no art. 23 da Constituição, que declara às Pessoas Jurídicas de Direito Público a competência de proteger o meio ambiente e promover programas de construção de moradias e melhorias nas condições habitacionais e de saneamento básico. Todos os entes federados possuem o dever comum de proteção ambiental, "pois a competência material comum impõem a responsabilidade solidária entre eles" (PADILHA, 2010, p. 208).

Como integrantes do Estado Federal, os municípios são dotados de auto-organização e autogoverno, dispondo de estrutura institucional e poder de polícia ambiental para agir em proteção ao meio natural nos limites e extensão dos impactos que afetem seus interesses, caracterizando-se uma competência em expansão. De acordo com dados de 2017 do IBGE, a Região Sul do país apresenta a maior presença de municípios com legislação ambiental, com percentual de 82,5. Contudo, para Dallari (2002, p.74-76), tal autonomia atribuída aos entes federados não se caracteriza como absoluta, visto que para concretização de sua autoadministração é necessário a observância na legislação estadual e federal

Se o propósito de eventual medida legislativa editada pelo ente estadual ou mesmo pelo ente municipal é reforçar os níveis de proteção ou mesmo afastar eventual déficit ou lacuna protetiva verificada na legislação federal, tal atitude legislativa, por si só, deve ser vista de forma positiva (MARINONI et al., 2018, p. 984).

O parágrafo único do referido artigo expõe a possibilidade de criação de normas infraconstitucionais para proteção e preservação de seus elementos e funções sociais para 
assegurar a qualidade de vida das populações atuais e futuras, na qual a afirmação se encontra sustentada pelo Princípio da Solidariedade Integracional, que busca assegurar a prevalência de uma estreita relação de solidariedade entre as presentes e as próximas gerações, de modo que estas últimas possam usufruir de forma sustentável dos recursos naturais, possibilitando assim, uma coexistência pacífica entre homem e natureza.

A Lei 6.938/81, que definiu a Política Pública Nacional do Meio Ambiente, consubstancia algumas normas e atos jurídicos administrativos que devem ser observados pelos órgãos competentes para o desenvolvimento socioeconômico e ambiental, com vistas à proteção da dignidade humana, entre eles: a) ação governamental na manutenção do equilíbrio ecológico, considerando o meio ambiente como um patrimônio público a ser necessariamente assegurado e protegido; b) racionalização do uso do solo, do subsolo, água, etc.; c) planejamento e fiscalização do uso dos recursos ambientais, acompanhados de controle de utilização, com cuidados e planejamentos especiais, tal como a recuperação do que já fora degradado e preservação de áreas ameaçadas de degradação, o que implica o acentuado papel dos órgãos locais, juntamente com a educação ambiental de toda a comunidade.

Ressalta-se a importância municipal ao passo em que é localmente que os recursos ambientais podem ser protegidos com ampla eficácia, dado a possibilidade de maior abrangência e ciência de todos os elementos que integram a questão ambiental local, isto é, compete ao município a promoção pertinente à organização territorial mediante ao planejamento e controle do uso, do parcelamento e da ocupação do solo urbano, conforme expresso na Constituição, em seu art. 182, que reafirma o objetivo do Poder Público municipal em ordenar o pleno desenvolvimento das funções sociais da cidade e a garantia do bem-estar de seus habitantes. O propósito do desempenho da competência legislativa municipal sempre será pautado no interesse local, “ seguindo aqui o critério constitucional da predominância do interesse [...] reforçada pela legitimidade democrática das instâncias políticas locais na adoção de medidas legislativas na seara ecológica, somada, por óbvio, à autonomia constitucional assegurada aos entes políticos municipais” (MARINONI et.al., 2018, p. 988).

Logo, para a garantia de um município ambientalmente sustentável e que atenda as exigências coletivas, é necessário versar sobre matrizes discursivas a respeito da sustentabilidade urbana, analisando-a junto aos casos globais, históricos e constitucionalizados, buscando auxílio no ordenamento jurídico em vigor e destacando os instrumentos de 
planejamento municipal contidos no Estatuto da Cidade para propor uma construção conjunta de orientações.

\subsubsection{Estatuto da Cidade}

O Estatuto da Cidade, regulado pela Lei 10.257 de 10 de julho de 2001, tem por função a criação de instrumentos para o desenvolvimento urbano, sendo o principal deles o Plano Diretor visando minimizar a especulação imobiliária e a regularização fundiária dos imóveis urbanos, além de arbitrar sobre o uso do solo, e da propriedade, adequando-a de modo a evitar o desvio de finalidade. Tal lei paira sobre o ordenamento jurídico como um mega princípio, os quais engloba vários direitos, nos quais direciona-se para o alcance da finalidade última de toda a ordem jurídica democrática: a dignidade da pessoa humana. Para Rosa $(2016$, p.87) "o ser humano, sendo este um animal possuidor de dignidade, necessita de um meio de vivência adequado e que permita subsistência digna. Ao se preservar o meio ambiente, se preserva a própria espécie humana”.

Em relação ao meio ambiente, a legislação é expressa sobre o tema

Art. $1^{\circ} \mathrm{Na}$ execução da política urbana, de que tratam os arts. 182 e $\underline{183 \text { da }}$ Constituição Federal, será aplicado o previsto nesta Lei.

Parágrafo único. Para todos os efeitos, esta Lei, denominada Estatuto da Cidade, estabelece normas de ordem pública e interesse social que regulam o uso da propriedade urbana em prol do bem coletivo, da segurança e do bem-estar dos cidadãos, bem como do equilíbrio ambiental.

Art. $2^{\circ}$ A política urbana tem por objetivo ordenar o pleno desenvolvimento das funções sociais da cidade e da propriedade urbana, mediante as seguintes diretrizes gerais:

I - Garantia do direito a cidades sustentáveis, entendido como o direito à terra urbana, à moradia, ao saneamento ambiental, à infraestrutura urbana, ao transporte e aos serviços públicos, ao trabalho e ao lazer, para as presentes e futuras gerações;

Aponta-se para a importância da planificação das cidades, valendo-se destacar sobre a regularização fundiária, na qual trata-se de um conjunto de medidas jurídicas, urbanísticas, ambientais e sociais que visam à regularização de assentamentos irregulares e à titulação de seus ocupantes, de modo a garantir o direito social à moradia, o pleno desenvolvimento das funções sociais da propriedade urbana e o direito ao meio ambiente ecologicamente equilibrado, apresentada no $\S 1^{\circ}$, art. $9^{\circ}$ da Lei $n_{13.465 / 17}^{\circ}$, delegando aos poderes públicos a implementação da medida. 
O Estatuto da Cidade pode ser qualificado como um programa de "redistribuição social do território urbano", o qual promove novos métodos para a lidar com as questões referentes as desigualdades socioambientais urbanas, sendo um deles a suspensão da produção da informalidade urbana obtidos através do controle social acerca das políticas urbanas, isto é, trata-se do poder-dever dos poderes municipais em consonância com o disposto no art. 30, VIII da Constituição Federal, executando-o mediante planejamento e controlo do uso, do parcelamento e da ocupação do solo urbano. Todavia, essas estratégias são apenas instrumentos para a realização de questões históricas de falta de planejamento, não podendo ser utilizada como solução para remediar situações geradas pela ausência de ações administrativas presentes.

\subsubsection{Plano Diretor}

O Plano Diretor refere-se basicamente a um instrumento de política urbana regulado pelo Estatuto da cidade, pelo Código Florestal e pela Lei do Parcelamento do Uso do Solo. Trata de assuntos pertinentes ao planejamento do território a fim de definir os meios de ocupação do município, isto é, refere-se a um mecanismo básico para política de desenvolvimento e expansão urbana, sendo construído democraticamente por meio da participação popular.

No plano, encontra-se o conjunto de orientações e propostas reproduzidas na forma de lei municipal, visando a garantia do desenvolvimento social e econômico, a organização do espaço e de seus diferentes usos, bem como as redes de infraestruturas, para curto, médio e longo prazo, na qual cabe a responsabilidade de execução a cada município.

Ocorre que, municípios pequenos, em sua maioria, não estabelecem determinações de zoneamento do uso do solo, ou seja, não dispõem de um processo de planejamento e ordenamento do uso e da ocupação de seus territórios e, da utilização dos recursos naturais ali existentes, e em grande parte, não possuem Plano Diretor ou encontram-se desatualizados. Insta mencionar que, pela lei, são obrigados sua implementação apenas em municípios com população superior a vinte mil habitantes, o que impossibilita a concretização de todos seus efeitos devido à falta de estrutura institucional administrativa, tal como profissionais adequados, meios e condições funcionais apropriados para o desenvolvimento do processo. 
Outro problema a ser apontado refere-se ao fato das ações do governo local restringiremse apenas a saciar determinada situação, ou seja, não há aplicação em planejamento de médio e longo prazo, demonstrando divergências com a norma vigente, o qual, em seu art. 30, dispõe como competência municipal a promoção adequada de distribuição territorial, mediante ao planejamento e controle do uso, parcelamento e ocupação do solo urbano. Destaca-se que a mobilização social e limitada é efetiva apenas para recebimento de recursos destinado a saúde e educação, não havendo conselhos tocantes a habitação ou necessariamente ao meio ambiente.

A definição de um Plano Diretor consistente e eficaz é a base para que as normas de planejamento de ocupações vinculadas as regras nele formuladas e eventuais diretrizes programáticas sejam concretizadas.

\subsection{Divergência entre a problemática ambiental e habitacional}

Verifica-se que o direito ao meio ambiente nem sempre é possível no caso concreto devido à urbanização agravada pelas desigualdades sociais, o que gera discussão em relação ao conflito de direitos fundamentais. Porém, considera-se o direito ao meio ambiente ecologicamente equilibrado como um "direito fundamental em sua dupla dimensão, dotado de uma dimensão tradicional subjetiva (individual) e uma dimensão objetiva, que expressa os valores almejados por toda a comunidade" (PADILHA, 2010 p.173), não podendo ser entendido nem alcançado pelos mecanismos jurídicos tradicionais, uma vez que representa a ruptura com o paradigma do Direito Clássico. O governante, junto com as demais organizações administrativas, deve valer-se do Princípio da Proporcionalidade, recurso este cabível quando há incompatibilidade entre as normas de direitos fundamentais, a qual tende a otimizar relativamente às possibilidades legais frente a outras prerrogativas concorrentes. Ocorre a ponderação de interesses, tal que não há uma hierarquia entre tais normas, e a solução dependerá da aplicação no caso concreto. Ressalta-se a importância do direito ambiental, devido seu caráter difuso, entretanto, é preciso a conciliação entre a preservação de áreas ambientais específicas e o direito constitucional a habitação, onde um não exclui o outro.

No momento em que o Estado se posiciona de maneira a legislar situações que por ele já foram defesas em lei, este pode estar ferindo seus próprios princípios constitucionais, a 
exemplo, o caso em que o poder público autoriza a posse legal de áreas de preservação permanente aos ocupantes ilegais desta, acarretando danos que atingem não apenas os moradores da região que tiveram seus interesses temporariamente supridos, mas as gerações futuras.

Discute-se: o indivíduo possui direito adquirido de pré-ocupação?

A doutrina e a jurisprudência não reconhecem o direito de pré-ocupação do solo, da mesma forma, o ser humano não possui o direito adquirido de poluir o meio ambiente ao se estabelecer em áreas protegidas. A hipótese de supressão da vegetação nativa só será possível em observância à Lei 12.651/12

Art. 8ํㅡ A intervenção ou a supressão de vegetação nativa em Área de Preservação Permanente somente ocorrerá nas hipóteses de utilidade pública, de interesse social ou de baixo impacto ambiental previstas nesta Lei.

Ocorre de fato a atuação do Poder Público, em suas atribuições, o dever de dar à população que reside nessas locais condições suficientes para aplicação de métodos objetivando minimizar a degradação ambiental sem causar danos à saúde e ao meio ambiente, tais como a implementação de programas que possibilitem o acesso a casa própria.

De acordo com Farias e Rosenvald (2017, p. 314) “qualquer atuação inferior ao patamar da função social será interpretada como abuso do direito de propriedade", dado que a função social almeja determinar que a propriedade se realize segundo os valores e interesses metaindividuais estipulados

Transfigura-se necessária a avaliação no caso concreto equilibrando-se os valores conflitantes e sustentando as justificativas apresentadas, a fim de que essas se tornem plenamente seguras a amparar quaisquer decisões que venham a ocasionar uma possível intervenção humana na natureza, de outro modo, é preciso, de acordo com Vanin (2015, p. 80), conciliar o desenvolvimento econômico com o bem-estar social e a preservação ambiental, superando planos emergenciais e intervenções fragmentadas que não auxiliam de maneira definitiva para a superação de problemas, passando a pensar na tarefa dos municípios de forma planejada, garantindo que os mesmos sejam ambientalmente sustentáveis. 


\subsection{Dificuldade de implementação de medidas satisfatórias e possíveis soluções}

A impunidade, a fiscalização deficiente, os processos de licenciamento negligentes, burla da legislação, ocultação de informações sobre os riscos, permissão ambiental das agências públicas, são alguns dos eventos que dão origem e caracterizam os diversos problemas ambientais. A questão da competência comum se torna um verdadeiro "obstáculo", na qual a atribuição de deveres a todos acaba se transformando no dever de ninguém.

Para Granziera (2014, p. 644-645), são três os principais problemas que prejudicam a sustentabilidade urbana: a interrupção de programas destinados à política ambiental, visto que a cada mudança do Executivo municipal há suspensão e substituição por outros sem eficácia e efetividade; a carência de aparato administrativo; e a insuficiência de vontade política para melhoria das condições de vida.

Pontos econômicos, políticos e sociais são os principais fatores que interferem na implementação de Planos Diretores em cidades menores. Falhas associadas ao sistema administrativo, como a ausência de verbas orçamentárias, podem ser classificadas segundo um efeito de ineficiência na aplicação da gestão pública, que ao mesmo tempo impedem e dificultam a construção de instrumentos jurídicos eficazes. A atribuição de competências, assim mencionado anteriormente, só poderá ser executada absolutamente pelo município se houver órgão ambiental competente para fiscalização, conforme dispõe o art. 15 da Lei Complementar 140 de 2011.

De acordo com a Lei 6.938/81, art. $3^{\circ}$, IV, “Toda pessoa física ou jurídica é responsável pelos danos causados ao meio ambiente". Isso se aplica aos municípios que devem ser responsabilizados pelos danos ambientais por omissão de fiscalização ou concessão de licenciamento ambiental. A omissão constitucional acarreta lacunas e sobreposições de competências ambientais, dificultando a atuação do poder de polícia ambiental, principalmente no que concerne à fiscalização do licenciamento para a construção de moradias.

As ocupações ilegais são desconsideradas em vários espaços, sendo pautas ausentes na aprovação de muitos projetos. Para tanto, é preciso que sejam reconhecidas a situações de risco, para que as medidas que foram formuladas e processadas sejam legitimadas, pois o "sucesso de um planejamento não depende do que é feito, mas como é feito" (VANIN, 2015, p.104). Insta 
mencionar que, tanto o direito ambiental quanto o direito à moradia são elencados como fundamentais, respaldados pela proibição do retrocesso social. Assim, na convergência destes, a supressão temporária de um para a efetivação do outro deve ser seguida de modo menos prejudicial à coletividade.

Para uma análise da resolução dos problemas destacados, é necessário observar o período de ocupação irregular, inclusive se teve início antes da vigência do Novo Código Florestal; a espécie da ocupação, habitacional ou para fins econômicos; apuração das condições financeiras do ocupante; verificação da possibilidade de regularização ocupacional; apuração do grau de impacto ambiental; e a disponibilidade de outras áreas para deslocar este contingente populacional (reassentamento). Ademais, ressalta-se que o referido código, ao flexibilizar suas diretrizes para permissão da supressão das APPs para interesse social, deixa para o Executivo a decisão da prevalência de interesses protetivos ambientais em detrimentos de demais convergências relacionadas aos direitos sociais.

Ambientalistas defendem a remoção, em contrapartida, cientistas sociais entendem que é preciso ocorrer a adequação das áreas para ocupação, ou seja, observa-se uma completa contradição dos pontos de vista e no controle desses riscos, o que constitui a lacuna estatal, promovendo a manutenção de uma situação de risco. Salienta Filho e Tabak (2016, p. 320) que o Estado e a coletividade ao depararem com riscos de uma atividade danosa ao ambiente, devem adotar as medidas mais benéficas "adotando-se os cuidados necessários na interpretação das normas e na implementação das políticas públicas, não se limitando este princípio, portanto, à análise realizada em licenciamentos ambientais".

O município tem a obrigação de remover as famílias que ocupam ilegalmente áreas próximas a mananciais, realocando-as em áreas que possam ser construídas habitações adequadas, através de projetos que viabilizem a efetivação do direito à moradia em um local apropriado e em condições dignas aos grupos sociais de baixa renda, assim como dispõe as diretrizes da Lei 11.977/09, que interpretada em consonância com o Estatuto da Cidade, tendem a finalidade de um mecanismo de incentivo à construção e à aquisição de unidades habitacionais pelas famílias com renda mensal inferior a dez salários mínimos, garantindo o bem-estar dos habitantes e o pleno desenvolvimento das funções sociais da cidade pautada na tutela jurídica do meio ambiente artificial. 
Outra possível solução é a declaração destes locais como Zona Especial de Interesse Social (ZEIS), na qual são regularizadas as ocupações, predominantemente residenciais localizadas neste perímetro, ou seja, junto aos órgãos federais e estaduais, deve-se realizar a elaboração de mapeamento e cadastramento de territórios já ocupados, para controle e inspeção.

Nesta perspectiva, em análise ao perfil do município de Assaí, vislumbra-se um avanço no desenvolvimento de seu novo Plano Diretor (Lei 1.693/2019) que reserva um capítulo próprio para tratar da qualificação ambiental da cidade, com programas de implementação e gerenciamento de recursos naturais, principalmente no tocante às áreas de mananciais, conforme o art. 63 , in verbis

\begin{abstract}
Art. 63. Este programa objetiva a implantação de um sistema de gestão para a conservação dos recursos naturais do município, em especial, os mananciais de abastecimento de água potável e as reservas de água subterrânea identificados como Macroárea do Manancial de Captação - MMC, com o objetivo de recuperar e implantar a faixa legal de mata ciliar em todos os córregos, atendendo o que contempla o novo Código Florestal lei $\mathrm{n}^{\mathrm{o}}$ 12651/2012 e suas atualizações. Visa ainda, definir as bacias hidrográficas como unidades territoriais de gestão, e também a identificação, cadastramento, conservação e monitoramento das áreas de reserva legal existentes em nosso Município, com o incentivo na preservação do ecossistema e corredores ecológicos.
\end{abstract}

Registra-se que o presente Plano estabelece ações integradas nos bairros próximos aos córregos, com fins a proporcionar a moradia digna para a população instalada de forma irregular, além da qualificação ambiental da área ocupada, propondo dentre outras medidas: o estudo da área de alocação (viabilidade técnica, orçamentária e consulta à comunidade), a realocação da população em situação irregular, a elaboração de projeto para o assentamento da população, demolição das construções irregulares/clandestinas e a qualificação urbana da área, etc.

De mais a mais, nota-se também progresso quanto a delimitação de zonas especiais de parcelamento (ZEP), voltados para a construção de habitações de interesse social, seguindo-se as diretrizes contidas na Lei Municipal 1.694/2019. Nesse sentido, a legislação local de parcelamento do solo urbano (Lei 1.697/2019), em seu art. 48 prevê o denominado "parcelamento de interesse social", destinado à população de baixa renda para proceder à “ (...) construção de habitação de interesse social vinculados a planos ou programas habitacionais governamentais, a serem implantados preferencialmente na Zona Especial de Parcelamento ZEP definida na Lei de Zoneamento e Uso e Ocupação do Solo”. 
Isto posto, conclui-se que os recursos mais apropriados para solucionar tais problemas resumem-se à implementação de mais políticas públicas voltadas à aquisição de domicílio adequado, a educação ambiental, valorização das propostas instituídas pelas organizações sociais como instrumento de recuperação e preservação ambiental, delimitação correta das áreas de mananciais e fiscalização adequada, assim como proposto pelo Plano Direto do município em análise.

\section{CONSIDERAÇÕES FINAIS}

A ineficácia de normas ambientais contribuiu para a situação atual, na qual constam milhares de famílias alojadas em locais impróprios para habitação, colocando em debate dois direitos essenciais à qualidade de vida: o direito constitucional à moradia e o direito ambiental sustentável, contrapondo-os como sendo independentes.

É evidente o conflito ao tratar da ocupação em áreas de preservação permanente, em especial, de mananciais nas zonas urbanas, na qual de um lado se tem o direito à moradia digna e de outro, o direito ao meio ambiente ecologicamente equilibrado e sadio, sendo este, um direito difuso, com características básicas, tais como sua enorme abrangência, indeterminação de seus destinatários, a indivisibilidade do objeto, a intensa conflitualidade e a sua duração efêmera e contingencial.

Observa-se que não bastam apenas direitos humanos de igualdade, liberdade e propriedade para a conquista de condições de vida digna, constatando-se que é imprescindível a manutenção do equilíbrio do meio ambiente enquanto um direito humano de fraternidade, que impõem, inclusive, a responsabilidade das atuais gerações para as futuras.

Para a efetivação do mesmo, é essencial em pequenos municípios, o desenvolvimento de um Plano Diretor eficiente para a restrição da ocupação irregular em áreas de proteção ambiental, garantindo conservação das áreas de mananciais e consequentemente, de bacias hidrográficas e vegetação local, além de diligências políticas que busquem sua concretização, principalmente no tocante a cidadãos menos favorecidos, garantindo-os as necessidades básicas 
adequadas. Desta forma, ao Poder Púbico compete a definição de políticas habitacionais voltadas à comunidade de baixa renda, como meio de garantir e certificar o direito à moradia digna como título de posse, auxiliando a inclusão social e a afirmação da cidadania, bom como a proteção ambiental ao restringir e condicionar o direito à propriedade, que deve atender sua função socioambiental, buscando o equilíbrio entre ambas.

\section{REFERÊNCIAS BIBLIOGRÁFICAS}

AGÊNCIA NACIONAL DE ÁGUAS (ANA). Atlas Brasil - Abastecimento Urbano de água: Paraná. Disponível

em: http://atlas.ana.gov.br/atlas/forms/analise/Geral.aspx?est=5\&mapa=sist. Acesso em: $04 \mathrm{dez}$. 2020.

ASSAÍ. Lei. 1.693/2019, de 10 de dezembro de 2019. Institui no âmbito do Poder Executivo Municipal o "Plano Diretor de desenvolvimento municipal de Assaí". Disponível em: https://docmunicipal.com.br/executivooutrosdocumentos/index/prefeitura-municipal-deassai/Wm1sc2RHVnlMbVpwYkhSbGNtTmhkR1ZuYjNKcFlRPT0=:TVRZNA==. Acesso em: 02 dez. 2020.

ASSAI. PR. Lei. 1964/2019, de 10 de dezembro de 2019. Dispõe sobre o zoneamento e o uso e ocupação nas áreas urbanas do município de Assaí e dá outras providências. Disponível em: https://docmunicipal.com.br/executivooutrosdocumentos/index/prefeitura-municipal-deassai/Wm1sc2RHVnlMbVpwYkhSbGNtTmhkR1ZuYjNKcFIRPT0=:TVRZNA==. Acesso em: 02 dez. 2020.

ASSAI. PR. Lei. 1.697/2019, de 10 de dezembro de 2019. Dispõe sobre o parcelamento do solo para fins urbanos no município de Assaí e dá outras providências. Disponível em: https://docmunicipal.com.br/executivooutrosdocumentos/index/prefeitura-municipal-deassai/Wm1sc2RHVnlMbVpwYkhSbGNtTmhkR1ZuYjNKcFlRPT0=:TVRZNA==. Acesso em: 02 dez. 2020.

BARCELlOS, Ana Paula de; BARROSO, Luis Roberto. O Começo da História. A Nova interpretação Constitucional e Papel dos Princípios no Direito Brasileiro. Revista da EMERJ, v. 6, n. 23, 2003

BRASIL. Constituição Federal de 1988. Promulgada em 5 de outubro de 1988. Disponível em: http://www.planalto.gov.br/ccivil_03/constituicao/constituição.htm. Acesso em: 09 jun. 2018.

BRASIL. Lei 6.766, de 19 de dezembro de 1979. Dispõe sobre o Parcelamento do Solo Urbano e dá outras providências. Disponível em: http://www.planalto.gov.br/ccivil_03/leis/16766.htm. Acesso em: 30 jun. 2018. 
BRASIL. Lei 6.938, de 31 de agosto de 1981. Dispõe sobre a Política Nacional do Meio Ambiente, seus fins e mecanismos de formulação e aplicação, e dá outras providências. Disponível em: http ://www.planalto.gov.br/ccivil_03/Leis/L6938.htm . Acesso em: 07 jul. 2018.

BRASIL. Lei 9.433, de 8 de janeiro de 1997. Institui a Política Nacional de Recursos Hídricos, cria o Sistema Nacional de Gerenciamento de Recursos Hídricos, regulamenta o inciso XIX do art. 21 da Constituição Federal, e altera o art. $1^{\circ}$ da Lei $n^{\circ} 8.001$, de 13 de março de 1990, que modificou a Lei $\mathrm{n}^{\mathrm{o}}$ 7.990, de 28 de dezembro de 1989.Disponível em: http://www.planalto.gov.br/ccivil_03/LEIS/19433.htm. Acesso em: 30 jun. 2018.

BRASIL. Lei 9.605, de 12 de fevereiro de 1998. Dispõe sobre as sanções penais e administrativas derivadas de condutas e atividades lesivas ao meio ambiente, e dá outras providências. Disponível em: http://www.planalto.gov.br/ccivil_03/LEIS/L9605.htm. Acesso em: 08 jul. 2018.

BRASIL. Lei 10.257, de 10 de julho de 2001. Regulamenta os arts. 182 e 183 da Constituição Federal, estabelece diretrizes gerais da política urbana e dá outras providências. Disponível em: http://www.planalto.gov.br/ccivil_03/leis/LEIS_2001/L10257.htm. Acesso em: 07 jul. 2018.

BRASIL. Lei 11.977, de 7 de julho de 2009. Dispõe sobre o Programa Minha Casa, Minha Vida - PMCMV e a regularização fundiária de assentamentos localizados em áreas urbanas; altera o Decreto-Lei no 3.365, de 21 de junho de 1941, as Leis nos 4.380, de 21 de agosto de 1964, 6.015, de 31 de dezembro de 1973, 8.036, de 11 de maio de 1990, e 10.257, de 10 de julho de 2001, e a Medida Provisória no 2.197-43, de 24 de agosto de 2001; e dá outras providências. Disponível em: http://www.planalto.gov.br/ccivil_03/_ato20072010/2009/lei/111977.htm. Acesso em: 07 jul. 2018.

BRASIL. Lei complementar 140, de 8 de dezembro de 2011. Fixa normas, nos termos dos incisos III, VI e VII do caput e do parágrafo único do art. 23 da Constituição Federal, para a cooperação entre a União, os Estados, o Distrito Federal e os Municípios nas ações administrativas decorrentes do exercício da competência comum relativas à proteção das paisagens naturais notáveis, à proteção do meio ambiente, ao combate à poluição em qualquer de suas formas e à preservação das florestas, da fauna e da flora; e altera a Lei no 6.938, de 31 de agosto de 1981. Disponível em: http://www.planalto.gov.br/ccivil_03/leis/LCP/Lcp140.htm. Acesso em: 30 jun. 2018.

BRASIL. Lei 12.651, de 25 de maio de 2012. Dispõe sobre a proteção da vegetação nativa. Disponível em: http://www.planalto.gov.br/ccivil_03/_ato20112014/2012/lei/l12651.htm. Acesso em: 17 jun. 2018.

BRASIL. Lei 13.465, de 11 de julho de 2017. Dispõe sobre a regularização fundiária rural e urbana, sobre a liquidação de créditos concedidos aos assentados da reforma agrária e sobre a regularização fundiária no âmbito da Amazônia Legal; institui mecanismos para aprimorar a eficiência dos procedimentos de alienação de imóveis da União. Disponível em: http://www.planalto.gov.br/ccivil_03/_ato2015-2018/2017/lei/113465.htm. Acesso em: 08 jul. 2018. 
CIRELLI, Gabriela L.; COSTA, Ilton Garcia da. Ética Ecológica em Crise e seu Enfrentamento: O Papel do Principio Responsabilidade na busca pela Sustentabilidade. In: Jaime Domingues Brito; Tiago Cappi Janini; Moacyr Miguel de Oliveira. (Org.). Responsabilidade do Estado. 1ed.Jacarezinho: UENP, 2018, v. 1, p. 153-167.

COMPANHIA DE HABITAÇÃO DO PARANÁ (COHAPAR). Pesquisa de necessidades habitacionais do $\quad$ Paraná: $2019 . \quad$ Disponível $\quad$ em http://www.cohapar.pr.gov.br/Formulario/PEHIS. Acesso em: 04 dez. 2020.

COSTA, Ilton Garcia; Cirelli, Gabriela LOPES . Resíduos Sólidos Nos Municípios e Sustentabilidade: A Crise Nos Serviços Públicos. DIREITO DA CIDADE, v. 10, p. 19661996, 2018.

COSTA, Ilton Garcia; CACHICHI, Rogério Cangussu D. ; CACHICHI, Zilda C. D. . Amor e Misericórdia: a flor e o fruto. In: Ivanaldo Santos; Lafayette Pozzoli. (Org.). Fraternidade e Misericórdia Um olhar a partir da justiça e do amor. 1ed.São Paulo: Cultor de Livros, 2016, v. 1, p. 93-100.

COSTA, Ilton Garcia da; ASSAHARA, Carolina Harumi. Descarte de Resíduos Agroindustriais como Atividade Potencialmente Poluidora: Tutela Ambiental e Dano Social. Revista HUMUS UFMA, v10, n 30 p. 21-45, 2020.

COSTA, Ilton Garcia; GOES, Winnicius Pereira . A Diretiva 2014/24/UE como Guia de Contratualizações Sustentáveis de Políticas Públicas Sociais. NOVOS ESTUDOS JURÍDICOS (ONLINE), v. 21, p. 656-690, 2016.

COSTA, Ilton Garcia; GONÇALVES, Aline M.. Da Sociedade Antiga à Sociedade Política e a Funcionalidade do Direito. NOMOS (FORTALEZA), v. 36, p. 205-224, 2016.

COSTA, Ilton Garcia da; GIACÓIA Gilberto. Parcerias Público - Privada: PPP e agências reguladoras, questões críticas. São Paulo: Verbatin, 2015.

COSTA, Ilton Garcia; LOPES, Soraya Saad (Org.) ; SILVA, Diego Nassif (Org.) . Inclusão Social: Desenvolvimento Sustentável e Meio Ambiente: Simpósio Iso Certos 2016. 1. ed. Bandeirantes PR: Redige, 2017. v. 1. 135p

COSTA, Ilton Garcia; MONTE, William R. Alkema ; DEMARCHI, Clovis . Considerações sobre a Gestão de Resíduos Sólidos no Brasil. In: Gabriel Real Ferrer; Marcelo Buzaglo Dantas; Maria Claudia da S. Antunes de Souza. (Org.). Sustentabilidade e suas Interações com a Ciência Jurídica. 1ed.Itajai: Univali, 2016, v. 1, p. 202-223.

DALLARI, Adilson Abreu; FERRAZ, Sergio (Coords). Estatuto da Cidade (Comentários à Lei Federal 10.257/2001). São Paulo: Ed. Malheiros, 2002.

FARIAS, Cristiano Chaves de; ROSENVALD, Nelson. Curso de Direito Civil: Direitos reais. $13^{\mathrm{a}}$ ed. Salvador: JusPODIVM, 2017.

FIGUEIREDO, Guilherme José Parvin de; LEUZINGER, Márcia Dieguez. Direito Ambiental das áreas protegidas. $1^{\mathrm{a}} \mathrm{ed}$. Rio de Janeiro: Forence Universitária, 2001. 
FILHO, Paulo Sérgio Ferreira. TABAK, Benjamin Miranda. Um limite temporal para regularização fundiária urbana em áreas de preservação permanente: as análises econômica e comportamental do direito e a proteção ao meio ambiente. Revista Veredas do Direito - Direito Ambiental e Desenvolvimento Sustentável. Belo Horizonte: Dom Helder, v. 13, n. 27, p. 315-340, Set./Dez. 2016.

FIORILlO, Celso Antonio Pacheco. Curso de Direito Ambiental Brasileiro. 14 ${ }^{\mathrm{a}}$ ed. São Paulo: Saraiva, 2012.

FREITAS, Vladimir Passos de. A Constituição Federal e a efetividade das normas ambientais. Revista CEJ/ Conselho da Justiça Federal, Centro de Estudos Judiciários, Brasília, v. 4 n. 10, p. 114-118, jan./abr. 2000.

GERVASONI, Tássia A.; SOUZA, Carina Lopes de. O Direito à Moradia e as contradições da Desigualdade Social. Revista Juris Poiesis, Rio de Janeiro. v.23, n.32, p.273-294, 2020.

GRANZIERA, Maria Luiza Machado. Direito Ambiental. São Paulo: Atlas, 2014.

INSTITUTO BRASILEIRO DE GEOGRAFIA E ESTATÍSTICA (IBGE). Perfil dos Municípios Brasileiros: 2017. Rio de Janeiro: IBGE, 2017.

JÚNIOR, Ruy de Azevedo Parahyba; SOUZA, Tatiana Santana de. Organizações sociais e políticas ambientais: parceria fundamental para a construção da sustentabilidade socioambiental. Agosto 2009. Disponível em: http: //www. joinpp.ufma .br/jornadas/joinpp IV/eixos/9_estados-e-lutas-sociais/organizacoes-sociais-e-politicas-ambientais-parceriafundamental-para-a-construcao-da-sustentab.pdf.

JÚNIOR, Zedequias de Oliveira. Áreas de Preservação Permanente Urbana dos Cursos D’Água - Responsabilidade do Poder Público e Ocupação Antrópica à Luz do Novo Código Florestal e seus Reflexos Jurídicos. Curitiba: Jaruá, 2014.

LOPES, Lauren Soares de Andrade; ZERBINI, Maiara Santana. Paz, Sustentabilidade e Desenvolvimento Humano. Paz, Inovação \& Sustentabilidade. Curitiba: Instituto Memória, p.48-70, 2016.

MACHADO, Paulo Affonso Leme. Direito Ambiental Brasileiro. 21 aed. São Paulo: Malheiros, 2013.

MANANCIAIS. Disponível em: http://www.mma.gov.br/cidades-sustentaveis/aguasurbanas/mananciais. Acesso em: 08 jun. 2018.

MARINONI, Luiz Guilherme; MITIDIERO, Daniel; SARLET, Ingo Wolfgang. Curso de Direito Constitucional. $7^{\text {a }}$.ed. São Paulo: Saraiva Educação, 2018.

MILARÉ, Édis. Direito do ambiente: a gestão ambiental em foco: doutrina, jurisprudência e glossário. 6 ed. São Paulo: Editora Revista dos Tribunais, 2009. 
NUNES, Danilo Henrique; LEHFELD, Lucas Souza; TOMÉ, Selma Cristina. A Mobilidade Urbana como forma de efetivação da função social do transporte público e concretização dos Direitos Sociais. Revista Juris Poiesis -Rio de Janeiro. Vol. 22 -n³0, pg. 23-49, 2019.

PADILHA, Norma Sueli. Fundamentos Constitucionais do Direito Ambiental Brasileiro. Rio de Janeiro: Elsevier Ltda, 2010.

ROSA, Maria Júlia Gabrigna. A preservação do meio ambiente como garantia dos princípios fundamentais. Paz, Inovação \& Sustentabilidade. Curitiba: Instituto Memória, p.71-88, 2016.

SCHRODER, Letícia Matos ; GARCIA, Lucyellen R. Dias ; COSTA, Ilton Garcia . Água Potável: direito à sadia qualidade de vida. In: Ilton Garcia da Costa; Gilberto Giacoia. (Org.). Parceria Público Privada - PPP e Agências Reguladoras, Questões Críticas. 1ed.São Paulo: Editora Verbatim, 2014, v. 1, p. 183-205.

SILVA, José Afonso. Direito Ambiental Constitucional. 10ªEd. São Paulo: Malheiros, 2013.

SOUZA, Maria Adélia Aparecida de. Geografias da desigualdade: globalização e fragmentação. Território: Globalização e Fragmentação. São Paulo: Editora Hucitec, p. 21-28, 1998.

VANIN, Fabio Scopel. Direito e Política Urbana - Gestão Municipal para a sustentabilidade. $1^{\text {a }}$ edição. Rio Grande do Sul: Educs, 2015.

Data de Submissão: 14/06/2020

Data de Aceite: 29/9/2020 